\title{
Analysis of Interoperability in the Queensland Disaster Management System
}

\author{
Amirhossein Eslami Andargoli, Peter Bernus and Hadi Kandjani \\ Centre for Enterprise Architecture Research and Management (CEARM) \\ School of ICT, Griffith University, Brisbane, Australia
}

Keywords: Interoperability, Disaster Management, Enterprise Architecture, GERAM.

\begin{abstract}
The increasing rate of natural and man-made disaster draws considerable attention from decision makers and planners in communities and governments. Disaster Management projects require the collaboration of several disaster management organizations and it results in heterogeneous systems. Interoperability of these heterogeneous systems is essential in order to enable effective and feasible collaboration among various organizations. This paper investigates interoperability issues in Queensland disaster management by analyzing current Queensland floods using Enterprise Architecture (EA) principles. Finally, a reference model is proposed to improve interoperability in Queensland disaster management system.
\end{abstract}

\section{INTRODUCTION}

The frequency of disasters and also their effects appear to have dramatically increased during the last century (Eshghi and Larson, 2008). Developing new technologies, better communication and media are some of the reasons for registering more disasters at the end of $20^{\text {th }}$ century compared to hundred years ago, however, this reason alone cannot justify why the number of disasters in the period of 2000-2005 (5 years) is higher than the period of 1990-1999 (10 years) (Eshghi and Larson, 2008).

Among these disasters, floods (possibly due to global climate change), increased in frequency such meteorological disasters cause extensive loss of property and human life. The frequency and intensity of floods in recent years have had impact on the Australian economy and human well-being. Floods with an annual cost of around \$340 million are Australia's most expensive natural hazard (Middelmann-Fernandes, 2009). Interoperability plays a pivotal role in enabling collaboration among disaster management organizations in order to reduce the effects of disasters and the loss of property and human life (Kapucu et al., 2010); (Chen et al., 2008); (Seifert, 2008). Enterprise Architecture (EA) is a discipline that allows the consideration of the establishment of a coherent and integrated information flow in the management and control of complex systems, and this paper uses and
EA approach to investigate how, through the improvement of interoperability within the system could be used to support more efficient and effective decision-making processes (Janssen et al., 2010); (Noran and Bernus, 2011). This paper demonstrates a method to address interoperability issues in disaster management by applying enterprise architecture principles, and uses the Queensland disaster management system as an example.

\section{INTROPERABILITY AND INTEROPERABILITY FRAMEWORKS}

Vallespir, Chen and Ducq (2005) define interoperability as the ability of one entity to accomplish tasks on behalf of another entity and the degree of the ability to jointly execute operations. A similar definition by Gottschalk (2009) is: "interoperability is an ability of diverse systems and organizations to work together." An interoperability framework is a set of concepts, standards and guidelines that are helpful for the discussion of how organizations interact with each other (EIF, 2004). There are several interoperability frameworks, although most only differ in their terminologies, assigning different names to the same concepts (Noran and Bernus, 2011). In Section 2.1 we review 
some of the major interoperability frameworks.

\subsection{The European Interoperability Framework (EIF)}

The aim of EIF was to guide e-government services development to ensure interoperability among governments throughout Europe (EIF, 2004). EIF defines three aspects of interoperability as follows:

- Organizational interoperability:

This aspect of interoperability intends to ensure shared/compatible goals and processes, and collaboration intent of administrations.

- Semantic interoperability:

This aspect of interoperability ensures a shared meaning of information that is exchanged among different entities.

- Technical interoperability:

This aspect of interoperability is concerned with technical issues of linking computer systems and services.

\subsection{The Interoperability Framework of Loos et al. (2011)}

Loos et al. (2011) propose an interoperability framework based on three interoperability concepts:

- Business interoperability:

This concept of interoperability is concerned with organizational aspects of interoperability. Business interoperability is an ability of enterprises to work with each other from a strategic point of view. The business interoperability domain comprises important matters such as cultural compatibility, trust, law, etc. (Loos et al., 2011).

- Process interoperability:

This aspect of interoperability is concerned with the ability of an entity (or enterprise) to accomplish tasks on behalf of another entity (or enterprise). Process interoperability requires internal and external coordination. External coordination comprises three levels as follow:

- Information flows: it deals with information exchange between humans, as well as applications.

- Material flows: it is described as physical transportation of objects between two locations.

-Financial flows: it deals with financial funds transfer between partners.

- Information systems interoperability:

This concept is concerned with the conditions of the successful exchange of information between enterprises (such as the compatibility of applications, data representation and semantics [information], and infrastructure) and are considered to be the components of information system interoperability.

\subsection{Chen's Interoperability Framework (Chen, 2006a; 2006b)}

Chen develops his interoperability framework based on the EIF, IDEAS, ERISA and ATHENA interoperability frameworks and defines three dimensions:

- Interoperability barriers:

This dimension is concerned with conceptual, technological, and organizational barriers to interoperability.

- Conceptual barriers: Syntactic (refers to the packaging and transmission mechanisms for data) and semantic (refer to the ability of two parties to agree on the meaning of data) differences of information are considered as conceptual barriers.

- Technological barriers: These barriers are concerned with incompatibility of information technologies (i.e. infrastructure)

- Organizational barriers: These barriers refer to incompatibility of organizational structures as well as understanding of the role, responsibility, and authority in the organization.

- Enterprise levels:

This dimension defines four enterprise levels for interoperations, as follows:

- The interoperability of data refers to the ability to find and share information from heterogeneous systems.

- The Interoperability of services refers to the ability to draw together and make use of functions of various enterprises and entities.

- The interoperability of processes is concerned with making different processes work together.

- The interoperability of business is concerned with the harmonization at the level of the organization/enterprise with the view to develop and do business together.

- Interoperability approaches:

According to ISO 14258 (as cited in Chen, 2006a) there are three ways to establish interoperability between entities:

- Integrated approach: All parties should agree on a common format for all models.

- Unified approach: use a common format at a Meta level. This Meta model allows the development of a mapping between models.

-Federated approach: in this approach, there is no common format. Hence, the parties should share 
their own ontologies in order for the other to understand the meaning of the models in the same way.

As shown above, various frameworks use essentially the same concepts to discuss interoperability, such as communication, data, infrastructure, organizational structure, process, etc. In the next section, we will use these concepts to explain interoperability issues in a disaster management system.

\section{INTEROPERABILITY, AND DISASTER MANAGEMENT}

Disaster and emergency decision makers need information from various resources (Gollery and Pohl, 2002). Disaster management requires multiple agencies to work together, and information needs to change rapidly as the disaster event evolves (Janssen et al., 2010). To address various aspects of disaster management a large number of disaster management organizations exist, resulting in a heterogeneous system (Noran and Bernus, 2011). Interoperability of these heterogeneous systems is essential in order to enable collaboration among these organizations (Dilmaghani and Rao, 2007). Therefore, collaboration and interoperability are essential foundations for effective disaster management (Waugh Jr and Streib, 2006).

Enterprise Architecture defines and interrelates data-, process-, resource- and organisational aspects of enterprises, and is therefore expected that it would be usable to be used as a guide when considering interoperability improvements to the design of the essentially distributed decision-making process in disaster management (Janssen et al. 2010); (Noran and Bernus, 2011). Enterprise architecture defines the fundamental structure of an organization and provides a holistic approach to the design of enterprises (Aier and Gleichauf, 2009). Enterprise Architecture (EA) as a discipline is an interdisciplinary approach, providing an effective combination of the contributions of relevant disciplines to the management of the evolution and change (Bernus and Nemes, 2003).

Therefore, by considering disaster management entities as a network of enterprises in change, or being re-architected, one could ensure the application of a holistic and interdisciplinary approach to the improvements of disaster management.
In particular, enterprise architecture frameworks, such as GERAM (Generalised Enterprise Reference Architecture and Methodology), aim at providing a complete set of tools, methods and models to be used by such enterprise engineering efforts (IFIPIFAC Task Force, 1999) and provide logical structure for organizing enterprise architecture endeavours (Dragstra, 2005), as well as ways to manage complexity (Janssen and Hjort-Madsen, 2007).

\section{RESEACRH METHODOLOGY}

The aim of this paper is to explore and analyse interoperability issues through a concrete case study, namely to consider the problems of disaster management as reported by the Queensland floods commission of inquiry report (2011). Data were collected from this report and other secondary resources. This research developed a reference model and process model, based on data that were gathered from these secondary sources, which are considered objective findings and are not subject to the authors' interpretation.

Therefore, it is expected that other persons with enterprise architecture and disaster management knowledge would be able to obtain the same outcome as the authors' research conclusions. As a result, this research is independent of human subjective interpretation and classifies as a positivist study.

This research follows a conceptual analytical approach (normally starting from assumptions, premises, and axioms) and derives a theory, model (as in this particular case), or framework (Jarvinen, 2000). This paper in particular emphasizes how to develop a model based on facts from secondary data (in this case literature and government reports).

\section{INTEROPERABILITY ISSUES IN THE QUEENSLAND DISASTER MANAGEMENT SYSTEM}

For the analysis, the authors will use Chen's interoperability framework because:

- In comparison with other interoperability frameworks (e.g. EIF) it is more complete and holistic, covering interoperability approaches, concerns, and barriers that are not found in other 
frameworks. However, pragmatic aspects of interoperability and cultural interoperability at the national and local levels are not included in this framework (Noran and Bernus 2011).

- Noran and Bernus (2011) have mapped the stages of disaster management to the GERA modelling framework with a full coverage of life cycle activities and also to Chen's interoperability framework (see Fig. 1). This can be useful for developing a reference model to address interoperability issues.

Below we demonstrate the use of Chen's dimensions to categorise interoperability issues. We use examples for each dimension: aspect / level / approach to interoperability.

\subsection{Interoperability Barriers (Conceptual Interoperability Issues)}

In the Queensland Floods Commission of Inquiry report (2011), Clerke indicates that using different activation level terminologies led to confusion in the disaster management system during the 2011 Queensland floods (disaster management teams use 'activation levels' to explain their status during different times of disaster e.g. 'alert', 'lean forward', 'stand up' and 'stand down'). For example, using different activation level terminologies by a Bundaberg local group in a teleconference with other disaster management groups led to confusion.

Inconsistency in information may make it unreliable (Clifford as cited in Mileti, 1995), and inconsistencies in warning message content may lead to delays in action (Drabek, 2001).

Consistency in the level of risks terminology and tone of warning message is critical. The message must be consistent in the way it conveys information about the level of risk, and the tone in which it is given (Fitzpatrick and Mileti as cited in (Paton, 2006)). This exemplifies a semantic interoperability problem, concerned with using the same meaning of the vocabulary (Vallespir et al., 2005).

Note that one aspect of semantic interoperability is concerned with the various understanding by people of the same concept. During the 2011 Queensland Floods drivers ignored road closure signs and continued to drive on flooded roads (Queensland Floods Commission of Inquiry, 2011). As different people have different conceptions about the danger of driving on flooded roads, educating people during the preparedness phase would reduce the issues about people having different preconceptions. Conversely, the researchers believe that overusing danger signals may condition the public to ignore important warnings in the future.

\subsection{Interoperability Concepts: Data Interoperability Issues (Communication)}

Communication (data interoperability) between entities is an essential characteristic of interoperability (Vallespir et al. 2005). For example, a disaster management system "depends on the flow of information between the local, district and state disaster management groups" (Queensland State disaster management plan, 2011). The local groups are in the front line of disaster response and if they do not have effective communication with the district group the disaster response would be ineffective (Queensland Floods Commission of Inquiry, 2011).

There are some examples of poor communication during the 2011 Queensland Floods. For example, the state level of Queensland sent resources to the region without consulting with the local group. Another example was sending the emergency message to the state group without informing the local group (Queensland Floods Commission of Inquiry 2011). Consequently, people in some areas did not receive the warning message in time, and this led to two deaths at Spring Bluff and two deaths at Murphys Creek (Queensland Floods Commission of Inquiry, 2011). During the 2011 Queensland floods, failures in communication made the disaster response less efficient in the Somerset region, with the Somerset local group losing communication with the district group for two days (Queensland Floods Commission of Inquiry, 2011).

Acknowledging that is a disaster situation it can be expected that sometimes there will be loss of communication, therefore, as a design principle, if one or several participants in a disaster situation cannot continue to accomplish their functions, the rest should be able to continue effectively (Noran and Bernus, 2011). As a consequence, in a situation where participants face communication loss they should be able to continue to function effectively. The above examples illustrated the importance of improving data interoperability in disaster management systems.

\subsection{Interoperability Approaches}

As discussed in the Section 2.3, there are three approaches for interoperability: integrated, unified, and federated. As previously shown, there is no 


\section{LIFE CYCLE OF ENTITIES DISASTER MANAGEMENT INTEROPERABILITY INVOLVED IN STAGES \\ ASPECTS \\ DISASTER MANAGEMENT}
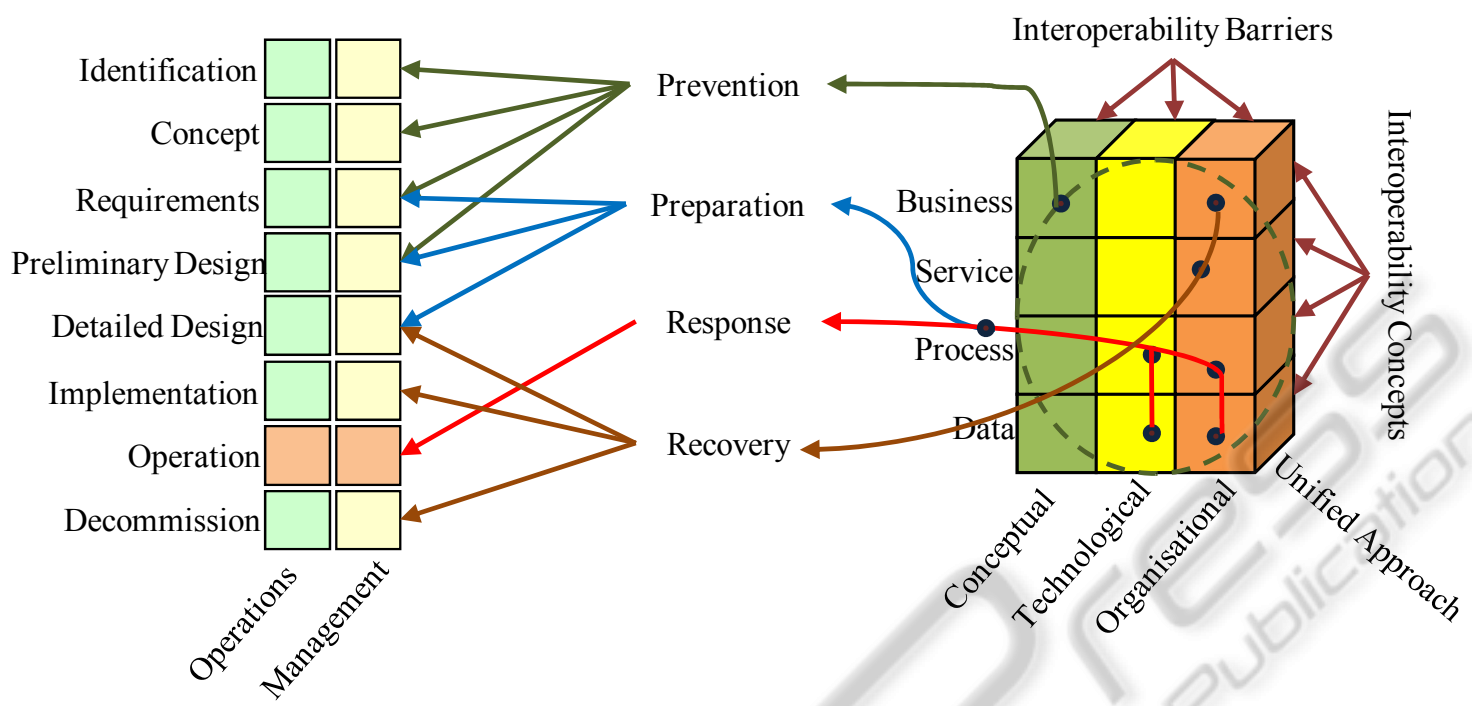

Figure 1: Disaster event mapping and modelling using a GERA-based formalism (left) and an interoperability framework (right) (adopted from Noran and Bernus (2011)).

general agreement on using the same evacuation terminology by local disaster management groups. There is no obligation for the district and local group to use the same terminology as each other or state group (Queensland Floods Commission of Inquiry, 2011). Therefore, it can be concluded that the Queensland management system has employed the federated approach, as there is no common format. To analyse the problem, one must consider two important features of disaster events: time shortage and complexity.

The federated approach needs enough time for negotiation and also the presence of multiple formats increases complexity. Therefore, the authors propose the use of a unified approach to eliminate these issues in the Queensland disaster management system. The unified approach needs advance negotiation to reach agreement on semantic, technological, and organizational interoperability requirements. Noran and Bernus (2011) argue that the unified approach requires the disaster management organizations to spend time together in order to reach agreement on conceptual interoperability issues.

In the next section, the authors explain how enterprise architecture can be useful for improving interoperability in disaster management. The main focus of this study was to investigate interoperability issues in the Queensland disaster management system, however, literatures confirms that interoperability issues exist in many disaster management systems. For example, the lack of attention to organizational interoperability among disaster responders to Hurricane Katrina in 2005 in United States (U.S.) led to difficulties in communication and reduced the overall effectiveness of the disaster management system (Waugh Jr and Streib, 2006).

\section{A MODEL FOR THE QUEENSLAND DISASTER MANAEGEMENT SYSTEM, ADDRESSING ISSUES OF INTEROPERABILITY}

We applied GERAM to develop a model for the Queensland disaster management. GERAM was selected because of its following distinct features: a) complete life-cycle coverage of enterprise entities, b) considering with equal importance the human and technical views of systems, c) ability to demonstrate relationships between life cycle and life history of entities of an enterprise. Figure 2 shows how GERAM was used to develop a reference model with the view to improve interoperability in the 
Queensland disaster management system. The arrows between entities in Fig. 2 represent interoperability requirements in the disaster management system.

Figure 2 shows the roles of various significant entities in improving interoperability in disaster management. The concept of collaborative network in disaster management plays critical role for effective disaster management to lessen interoperability issues, because a hallmark of collaborative networks is that they develop preparedness ahead of time for joint action (Noran \& Bernus, 2011; Kapucu et. al., 2010; Waugh Jr and Streib, 2006).

Figure 2 represents the whole of the system and the arrows show important interoperation between entities. The model shows how Population may influence Government and as a result change legislation. Population has an influence on the concept, requirement, and preliminary design of the management part of the Government. Government is a regulatory body responsible for the identification, concept development, requirements specification, preliminary design, detailed design, implementation, and operation of Disaster Management Laws. Also, another important interoperability requirement is that between the Population and the Disaster Management Taskforce (DMTF).

The need for a DMTF is identified and conceptualized by Disaster Management Collaborative Network (DMCN) in order to save human life and property. The DMCN is developed to integrate disaster management efforts. Task Force Reference Models are developed to keep the knowledge from past experiences and exercises for using in the future. DMTF uses Taskforce reference model to decrease the time of response and improve disaster management efficiency. Taskforce reference model and The DMCN together are responsible for specifying the requirements, preliminary designing, detailed designing, building, operation, and decommission of Disaster management taskforce.

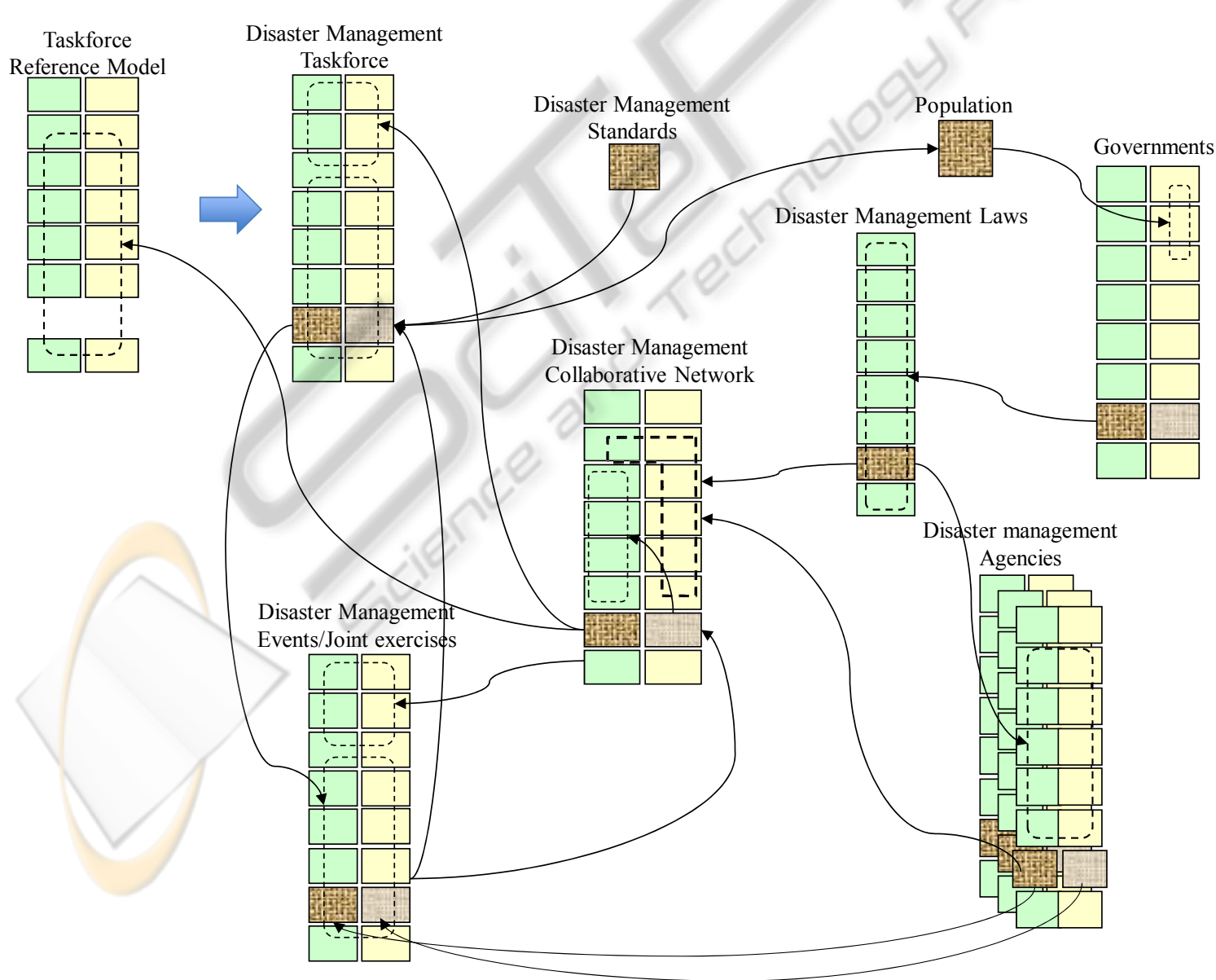

Figure 2: Interoperability of disaster management system using GERA modelling framework. 
The DMCN develops the requirements, preliminary design, detailed design, building or implementation of the Reference Model for the DMTF.. Note that after decommissioning a DMTF, the DMCN updates the knowledge from experiences and the lessons learned from past events and exercises and this is recorded in an evolving Taskforce Reference Model. Disaster management standards have influence on the operation of the Disaster Management Taskforce, as Disaster management standards provide guidelines and constraints for ensuring effective disaster management. The main goal of DMTF is to save human life and property, and a DMTF can be created on demand, based on the Reference model, almost instantaneously.

The DMCN identifies and conceptualizes the Disaster event. In this case, it means The DMCN is responsible for the mitigation stage of disaster events, while the DMTF is responsible for the preparedness, response, and recovery stages of disaster events.

Also, interoperability between DMTF within the DMCN and Disaster Management Organizations is important because all of these contribute to the operation disaster management. DMOs include: a. State Disaster Management Group (SDMG), District Disaster Management Group (DDMG), Local Disaster Management Group (LDMG), and b. all Disaster Management Agencies (DMA) such as Emergency Management Queensland (EMQ) Queensland Police Service (QPS) and State Emergency Service (SES). Disaster management Laws have an impact on the design (policies, principles of design, processes and procedures) of all Disaster Management Organizations, the DMCN, and the DMTF to ensure effective participation and response.

Disaster Management Laws (DMLs) are being used throughout the concept development, specification, preliminary design, detailed design, and implementation or building of DMOs. DMOs, taking into account DMLs, have to jointly develop the initial form of the Disaster Management Collaborative Network, although after initial creation the Network is responsible for its own detailed design, after the specified the requirements, preliminary design, detailed design of the management of the Network, and appointed ('built'), the management of the Disaster Management Collaborative Network. Importantly the Network, from time to time, self-designs, i.e., the DMCN is expected to adapt itself to changing conditions.

\section{CONCLUSIONS}

This paper investigated interoperability issues in disaster management and illustrated a process using enterprise architecture principles and frameworks that could be used to address interoperability issues, and this was illustrated through the Queensland disaster management system. As explained before, interoperability has various dimensions (like communication-,cultural- and, organizational-), and this research has, through secondary data analysis, indeed found examples of these in the Queensland disaster management system. Our future research intends to study organizational design problems from the interoperability perspective, and how these can be overcome in disaster management.

\section{REFERENCES}

Aier, S. \& Gleichauf, B. 2009. Towards a sophisticated understanding of service design for enterprise architecture. In Proc ICSOC'2009. LNCS 5472. Berlin : Springer, pp316-326.

Bernus, P. \& Nemes, L. 2003. Introduction to enterprise architecture. In: Bernus, P., Nemes, L. \& Schmidt, G. (Eds.) Handbook on enterprise architecture . Berlin : Springer.

Chen, D. 2006a. Enterprise interoperability framework. Proceedings of Enterprise Modelling and Ontologies for Interoperability, in Michele Missikoff, Antonio De Nicola, Fulvio D'Antonio (Eds.): Proc EMOIINTEROP'06. CEUR Workshop Proc, 200. p5

Chen, D. 2006b. Framework for enterprise interoperability. In Panetto, H. and Boudjlida, N (Eds) IFAC Ei2N Workshop on Interoperability for Enterprise Software and Applications. pp77-88.

Chen, R., Sharman, R., Chakravarti, N., Rao, H. R. \& Upadhaya, S. J. 2008. Emergency response information system interoperability: development of chemical incident response data model. Journal of the Association for Information Systems, 9, 200-230.

Dilmaghani, R. B. \& Rao, R. Hybrid communication infrastructure and social implications for disaster management. International Conference on System Sciences, 2007 Hawaii. IEEE, 22-22.

Drabek, T. E. 2001. Disaster warning and evacuation responses by private business employees. Disasters, $25,76-94$.

Dragstra, P. 2005. Enterprise Architecture. The Selection Process of an Enterprise Architecture Toolset to Support Understanding and Governing the Enterprise, Technische Universiteit Eindhoven, Eindhoven .

EIF. 2004. European interoperability framework for paneuropean egovernment services. IDA working document, version, 2.

Eshghi, K. \& Larson, R. C. 2008. Disasters: lessons from 
the past 105 years. Disaster prevention and management, 17, 62-82.

IFIP IFAC Task Force. 1999. GERAM: Generalised enterprise reference architecture and methodology version 1.6.3.

Gollery, S. J. \& Pohl, J. G. 2002. The Role of Discovery in Context-Building Decision-Support Systems. Collaborative Agent Design (CAD) Research Center, 55.

Gottschalk, P. 2009. Maturity levels for interoperability in digital government. Government Information Quarterly, 26, 75-81.

Government, Queensland. 2011. Queensland State Disaster Management Plan, 1-54.

Government, Queensland. 2011. Queensland Floods Commission of Inquiry, 1-323.

IBISWORLD, 2011. Queensland floods: The economic impact, 1-8.

Janssen, M. \& Hjort-Madsen, K. 2007. Analyzing enterprise architecture in national governments: The cases of Denmark and the Netherlands. In Proc HICSS'07. IEEE, 218a-218a.

Janssen, M., Lee, J. K., BharosaA, N. \& Cresswell, A. 2010. Advances in multi-agency disaster management: Key elements in disaster research. Information Systems Frontiers, 12, 1-7.

Jarvinen, P. 2000. Research questions guiding selection of an appropriate research method, in In Proc $8^{\text {th }}$ European Conf on Information Systems, pp124-131

Kapucu, N., Arslan, T. \& Demiroz, F. 2010. Collaborative emergency management and national emergency management network. Disaster prevention and management, 19, 452-468.

Kuehn, A., Kachewsky, M., Kappeler, A., Spichiger, A. \& Riedl, R. 2011. Interoperability and information brokers in public safety: an approach toward seamless emergency communications. Journal of theoretical and applied electronic commerce research, 6, 43-60.

Loos, P., Werth, D., Balzert, S., Burkhart, T. \& Kamper, S. 2011. Handbook of research in enterprise systems. In: Kumar, S., Esteves, J. \& Bendoly, E. (eds.) Handbook of research in enterprise systems. Response Books.

Middelmann-Fernandes, M. H. 2009. Review of the Australian Flood Studies Database In: Department of resources, E. A. T. (ed.). Canberra : Geoscience Australia.

Mileti, D. S. Factors related to flood warning response. US, Äiltaly Research Workshop on the Hydrometeorology, Impacts, and Management of Extreme Floods, Perugia, Italy, 1995. 13-17.

Noran, O. \& Bernus, P. (2011). Effective disaster management: an interoperability perspective. Lecture Notes in Computer Science, 7046, 112-121.

Paton, D. 2006. Warning Systems: Issues and considerations for warning the public. Douglas Paton

Seifert, J. W. Reauthorization of the E-Government Act: A brief overview. 2008. Congressional Research Service, Library of Congress.

Vallespir, B., Chen, D. \& Ducq, Y. 2005. Enterprise modelling for interoperability. Proc $16^{\text {th }}$ IFAC World Congress. IF AC Papers online. 1529-1529

Waugh Jr, W. L. \& Streib, G. 2006. Collaboration and leadership for effective emergency management. Public Administration Review, 66, 131-140. 